\title{
Customer Satisfaction Towards ATM Service In Nepalese Banking Sector
}

\begin{abstract}
This research is intended to examine the relationship between reasonability of fee charged, choice of ATM, usage of service and post purchase behavior and customer satisfaction. The research has used primary sources of data. A well-structured questionnaire was designed to collect data from 200 respondents using purposive sampling technique. The data was analyzed using correlation. The findings revealed that there was a positive and significant relationship between reasonability of fee charged, choice of ATM, usage of service and post purchase behavior and customer satisfaction. The research is afresh study in the field of banking sector in Nepalese context. There is an implication of research in the banking sector.
\end{abstract}

Keywords: Customer Satisfaction, Reasonable Fee, usage of service, Purchase behavior, and Choice of ATM

\section{Introduction}

In innovation process, banks have to decide which products banks constraints wish to sell, whether banks wish to build those products themselves, how banks should deliver, and why banks wish to deliver those products to customers (Raihan et al., 2001). Innovation is the skill of in capacitating toward improvement of financial and other services. It emerges when a new or changed product or service is announced to the market, or when a new or changed process is used in a commercial condition. Mcandrews (2003) explains ATMs can offer significant advantages to both banks and customers. The machines can enable depositors to withdraw and deposit cash at more convenient times and places than during banking hours at branches. At the same time, by automating services that were previously completed manually, ATMs can reduce the costs of servicing some customer demands. These potential advantages are multiplied when banks share their ATMs with others, allowing depositors of other banks to access their accounts through any bank's ATM. The decision by banks to share their ATMs is partially determined by the terms under which different banks agree on. There are several prices that can be charged or collected by the three main parties involved in an ATM transaction, the cardholder or the customer, the cardholder's bank, and the ATM banking transaction made through ATM owner. Saeed et al. (2015) observed stiff competition

* Lecturer, Shanker Dev Campus Trubhuvan University, Nepal

Email ID: goetj15@gmail.com 
in the banking industry due to which the significance of customer satisfaction has grown tremendously. The study identified five quality dimensions that play a vital role to fill the gap between customer expectation and customer satisfaction. Five quality dimensions include reliability, privacy, reputation, empathy and tangibility. Numerous studies have agreed that customer expectations encompass more than one aspect of the service package (Johnston, 1995; Chase, 1978). The variables considered in previous researches are quality, assurance, reliability etc. in relation to customer satisfaction whereas this research mainly considered the variable like reasonability of fee charged, choices of ATM, post purchase behavior, usage of ATM. The previous researches considered only particular bank or between two banks or more banks but this research is carried out considering all the Nepalese banks that's issue ATM cards as well as the customers using any banks ATM cards. The objective of the research is to analyze the factors affecting customer satisfaction from ATM services in Nepalese banking sector. This examination is quantitative to give learning into the examples that have influenced the satisfaction of the ATM customers.

\section{Literature Review and Hypothesis Formulation Customer Satisfaction}

Customer satisfaction is a measure of expectation of a consumer's products and services supplied by a company (Islam et al., 2007). In other words, Jhandir (2012) stated customer as a stakeholder of an organization who provides payment in exchange for the offer provided to him/her by the organization with the aim of fulfilling a need and to maximize satisfaction. Customer satisfaction is the outcome felt by buyers who have expectation. Customers are satisfied when their expectations are met and delighted when their expectations are exceeded (Jothi, 2001). On the other hand, Motwani and Shrimali (2013) found ATM as one of the best services offered by banks which offers a appropriate way to customers to avoid unsatisfying queues in banks. Moreover, this study reveals significant impact of demographic factor on awareness level about ATM services. Koirala and Shrestha (2012) confirmed service quality has influence on customer satisfaction in Nepalese commercial banking sector undertaking.

\section{Reasonability of Fee Charged}

The bank charge fee for improvement of new ATM card and also if customers request new ATM card when their old ATM card gets expired, lost, damaged or blocked (Jegede, 2014). However, Banks' setting of ATM fees varies from one country to another due to differences in regulatory policy. Motwani and Shrimali (2013) argued that banks should not charge users for ATMs usage. The justification of this argument is built on the idea that customers will not be satisfied if their banks charge them against the usage of ATMs while they use their cash balances in credit facilities and obtain credit interest on that money (Hubbard, 2009). Similarly, Omar et al. (2011) found positive relationship between fee charged for ATM service and customer satisfaction and customer loyalty. 


\section{Choice of ATM}

It refers to the opportunity or power to choose ATM between two or more banks. It also refers to selection and usage of ATM of particular bank among various other banks in respect to its superiority. Customer can make their choice of ATM on the basis of some factors such as security and trust, convenience in use, easy available location of ATM outlets, speed transaction facilities, example of others, etc. Thus, while choosing ATM of a particular bank customer takes care of these things and is known as factors affecting the choice of ATM (Singh 2009). On the other hand, Mcandrews (2003) examined that secure and convenient location, adequate number of ATM, user-friendly system and functionality of ATM play important role in customers' satisfaction. While, Moutinho and Shrimali (2013); Dilijonas et al. (2009) found positive and significant relationship between adequate number of ATMs, convenient and secure location, user-friendly system, speed, minimum errors, high uptime, cash backup, cost and service coverage with customer satisfaction od ATM users. Moreover, Joseph and Stone (2003) revealed that the selection and usage of ATM are essential service quality aspects of ATM to increase customer satisfaction.

\section{Usage of Services}

It refers to the purpose for which services are most often used by customers. ATM does not mean the plastic card and PIN (Personal Identification Number) but the services for which you can use it are the most important part. These services are cash/ cheque deposit, fast cash withdrawal, view account balances and mini statements, balance inquiry, make fund transfer and utility payments and request a cheque book or account statement (Singh, 2009). Similarly, Shamsuddoha et al. (2010) found that cash withdrawal, balance inquiry, cash deposit, fund transfer and cheque book requisition are the main services consumed by the customers who use ATM. In addition, this study found positive and significant relationship between frequency of ATM usage service, fee charged and convenient location with customer satisfaction. Moreover, Motwani and Shrimali (2013) revealed that 24 hours service accuracy, convenient location, etc. are the main factors of customer satisfaction.

\section{Post Purchase Behavior}

Post-Purchase Behavior is the stage of the buyer decision process when a consumer will take additional action. And, it is purely based on the satisfaction or dissatisfaction level of customers (Islam et al., 2007). Similarly, the consumer's level of satisfaction or dissatisfaction is directly related to the varying relationship between their initial expectations of the product (pre-purchase), and their perception of the actual performance of the product (post-purchase) (Madawaki et al., 2014). Similarly, Parvin and Hossain (2010) found that on an average, the debit card users are satisfied from the availability of cash in ATM booth. On the other hand, Kumbhar (2011) showed that after the post purchase, the consumer perceives the product's performance as matching their expectations, or even exceeding them, they will be "satisfied". Moreover, Darch and Caltabiano (2004) found the positive and significant relationship between post purchase behavior and customer satisfaction from ATM services. 


\section{Hypothesis Development}

$H_{1}$ : Reasonability of fee charged is positively related to customer satisfaction in Nepalese banking sector. $\mathrm{H}_{2}$ : Choice of ATM is positively related to customer satisfaction in Nepalese banking sector $H_{3}$ : Usage of services is positively related to customer satisfaction in Nepalese banking sector. $H_{4}$ : Post purchase behavior is positively related to customer satisfaction in Nepalese banking sector.

\section{Research Methodology}

The main purposes of the study is to analyze the observation of customer towards the preference of ATM service quality of Nepalese banking sectors. This study adopts descriptive research design for fact finding and identifies adequate information about factors affecting customer satisfaction. The descriptive and correctional research design have been used to test the purpose of the study. The study also employs causal comparative research design to identify the reasonability of fee charged and choices of ATM at Nepalese banking sector. This research study has based on primary source of data. The respondents have been chosen a purposive technique out of more than ten hundred thousand users of ATM. Data has collected from the users of ATM card holders from Nepalese banking sector. Rigorously the primary data has used for the study and primary data has collected by distributing the structured questionnaires. 250 questionnaire has distributed but responded only 200 of the total of 250 respondents that has rated 80 percent. . Primary data are analyzed using the SPSS package. Descriptive statistics and correlation tools are used through SPSS package in order to drive the meaningful relationship among the dependent and independent variables. The methods of data analysis consist mean and weighted average values of various dimensions such as reasonability of fee charged, usage of services, choice of ATM and post purchase behavior and Kendal's correlation coefficients which examines the relationship of various factors affecting customer attraction of customers of Nepalese banking sector.

\section{Results and Discussion}

Table 1

\begin{tabular}{|l|c|c|c|c|c|c|c|}
\hline \multirow{2}{*}{ Factors } & \multicolumn{5}{|c|}{ Ranks } & Mean & Overall \\
\cline { 2 - 8 } & 1 & 2 & 3 & 4 & 5 & & Rank \\
\hline Reasonability of fee charged & 74 & 58 & 34 & 24 & 10 & 2.34 & I \\
\hline Post purchase behaviour & 10 & 23 & 54 & 76 & 45 & 3.15 & III \\
\hline Choice of ATM & 30 & 23 & 54 & 47 & 46 & 3.19 & IV \\
\hline Usage of services & 52 & 23 & 67 & 34 & 24 & 2.94 & II \\
\hline
\end{tabular}

Ranking Scores of the Important factors that Mostly Influence the Customer satisfaction level from the ATM Services.

(Source: Field survey, 2020)

Table 1 indicates the respondent responses on ranking scores of the important factors that mostly influence the customer satisfaction level from the ATM services. Mean rank score 
for the "reasonability of fee charged" is 2.34 making it the most important factor influencing customer satisfaction level ATM services. The second most important factor is "Usage of services" has been ranked second by the respondents with the mean score of 2.94. Mean score for "post purchase behavior" and "choice of ATM" is regarded as the least important factors and are ranked as third and fourth respectively.

Table 2

Ranking Scores of the Most Useful Services Provided by ATM

\begin{tabular}{|l|c|c|c|c|c|c|c|}
\hline \multirow{2}{*}{ Factors } & \multicolumn{5}{|c|}{ Ranks } & \multirow{2}{*}{ Mean } & Overall Rank \\
\cline { 2 - 7 } & 1 & 2 & 3 & 4 & 5 & & \\
\hline Cash withdrawal & 73 & 56 & 43 & 20 & 8 & 2.03 & I \\
\hline Balance inquiry & 66 & 43 & 42 & 6 & 43 & 2.45 & II \\
\hline Fund transfer & 35 & 15 & 23 & 69 & 58 & 3.16 & V \\
\hline Mini statement & 37 & 74 & 16 & 56 & 17 & 3.01 & III \\
\hline Utility payment & 23 & 43 & 48 & 65 & 21 & 3.12 & IV \\
\hline
\end{tabular}

(Source: Field survey, 2020)

Table 2 indicates the respondent responses on ranking scores of the most useful services provided by ATM. Mean rank score for the "cash withdrawal" is 2.03 making it the most useful service provided by ATM. The second most useful services provided by the ATM are "balance inquiry" with mean score of 2.45. "Mini statement" service of ATM has been ranked third by the respondents with the mean score of 3.01. Mean score of "utility payment" and "fund transfer" are 3.12 and 3.16 respectively and are ranked as fourth and fifth respectively.

Table 3

\begin{tabular}{|l|c|c|c|c|c|c|c|}
\hline \multirow{2}{*}{ Factors } & \multicolumn{5}{|c|}{ Ranks } & \multirow{2}{*}{ Mean } & Overall Rank \\
\cline { 2 - 6 } & 1 & 2 & 3 & 4 & 5 & & I \\
\hline Machine out of order & 94 & 26 & 18 & 32 & 30 & 2.14 & II \\
\hline Card gets blocked & 34 & 66 & 45 & 36 & 19 & 2.49 & III \\
\hline Machine out of cash & 26 & 32 & 38 & 79 & 25 & 3.18 & IV \\
\hline No printing Statement & 13 & 34 & 27 & 89 & 37 & 3.42 & V \\
\hline Old notes & 14 & 23 & 13 & 67 & 83 & 3.98 & \\
\hline
\end{tabular}

Ranking scores of the Type of Problems Respondents Face Most Often (Source: Field survey, 2020)

Table 3 indicates the respondent responses on ranking scores of the type of problem faced most often while using ATM services. Mean rank score for the "machine out of order" is 2.14 making it the most problem faced by customers while using ATM services. The second most 
problem faced by customers of commercial banks is "card gets blocked" with mean score of 2.49. "Machine out of cash" type of problem faced by customers has been ranked third by the respondents with the mean score of 3.18. Mean score for "no printing statement" and "old notes" are 3.42 and 3.98 respectively and are ranked as fourth and fifth respectively.

Table 4

\begin{tabular}{|l|c|c|c|c|c|c|c|}
\hline \multirow{2}{*}{ Factors } & \multicolumn{9}{|c|}{ Ranks } & Mean & Overall \\
\cline { 2 - 8 } & 1 & 2 & 3 & 4 & 5 & & Rank \\
\hline Security and trust & 64 & 26 & 23 & 42 & 45 & 2.14 & III \\
\hline Speed transactions & 23 & 54 & 44 & 52 & 27 & 2.12 & II \\
\hline Convenience in use & 46 & 37 & 76 & 34 & 7 & 2.34 & IV \\
\hline Near location of ATM outlets & 29 & 14 & 19 & 84 & 54 & 3.09 & V \\
\hline Consistency in service delivery & 63 & 73 & 17 & 24 & 23 & 1.62 & I \\
\hline
\end{tabular}

Ranking Scores of the Reasons for Choosing ATM Services of the Bank

(Source: Field survey, 2020)

Table 4 indicates the respondent responses on ranking scores of the reasons for choosing ATM services of the bank. Mean rank score for the "consistency in service delivery" is 1.62 making it the most important reason for choosing ATM services of the bank. The second most important reason for choosing ATM service of the bank is "speed transactions" with mean score of 2.12. "Security and trust" is one of the reasons for choosing ATM services of the bank which has been ranked third by the respondents with the mean score of 2.14. Mean score for "convenience in use" and "near location of ATM outlets and branches" are 2.34 and 3.09 respectively and are ranked as fourth and fifth respectively. The least important reasons for choosing ATM services of the bank are "convenience in use" and "near location of ATM outlets and branches" whereas the most important reason for choosing ATM services of the bank is its consistency in service delivery.

Table 5

Kendall's Correlation Matrix for the Dependent and Independent Variables

\begin{tabular}{|c|c|c|c|c|c|c|c|}
\hline Variables & Mean & S. dev. & REFC & COA & USAG & PURCH & CS \\
\hline REFC & 3.37 & 0.91 & 1 & & & & \\
\hline COA & 3.04 & 0.83 & 0.02 & 1 & & & \\
\hline USAG & 2.87 & 0.68 & $0.06^{* *}$ & $0.20^{* *}$ & 1 & & \\
\hline PURCH & 2.91 & 0.63 & $0.05^{*}$ & $0.03^{* *}$ & 0.37 & 1 & \\
\hline CS & 3.07 & 0.58 & $0.87^{* *}$ & $0.15^{* *}$ & $0.23^{*}$ & $0.89^{* *}$ & 1 \\
\hline
\end{tabular}

Source: SPSS results based on responses on survey questionnaire

Notes: The asterisk signs $\left(^{* *}\right)$ and $\left(^{*}\right)$ indicate that the results are significant at 1 percent and 5 percent level respectively.

Table 5 shows the Kendall's correlation coefficients between different variables use in this study. The correlation coefficients are based on the primary data collected from 25 sample 
banks. The CS (customer satisfaction) is dependent variable. The independent variables are REFC (reasonability of fee charged), COA (choice of ATM), USAG (usage of service) and PURCH (post purchase behavior). Customer satisfaction (CS) is the degree of satisfaction provided by the goods and services, reasonability of fee charged is amount of money charged by the bank for various services, Choice of ATM is power to choose ATM of different banks, usage of service is the purpose for which services are most often used by customers and post purchase behavior is the stage of the buyer decision process when a consumer will take additional action. The result shows that reasonability of fee charged is positively correlated to customer attraction. It indicates that more the fee charged for ATM service is reasonable, higher would be the customer satisfaction. Likewise, choice of ATM is positively related to customer satisfaction. It indicates that more the choice of ATM, higher would be the customer satisfaction. Similarly, usage of service is positively related to customer satisfaction. It indicates that increase in the usage of service leads to increase in customer satisfaction. Likewise, post purchase behavior is positively related to customer attraction indicating that better the post purchase behavior, higher would be the customer attraction.

\section{Conclusion}

The study reveals that utility payment and fund transfer are the least useful services provided by ATM. The most often faced problem by the users of ATM services are machine out of order and cards getting blocked in the ATM. The least important reasons for choosing ATM services of the bank are "convenience in use" and "near location of ATM outlets" whereas the most important reason for choosing ATM services of the bank is its consistency in service delivery.

The study also reveals that reasonability of fee charged, choice of ATM, usage of service and post purchase behavior have positive relationship with customer satisfactions of Nepalese banking sector. The study concludes that the most influencing factor for determining the customer satisfaction on ATM service is post purchase behavior followed by reasonability of fee charged and choice of ATM. The study also concludes that post purchase behavior plays the most influencing role while choice of ATM plays a least important role in determining the customer satisfaction on ATM service in Nepalese banking sector.

\section{References}

Chase, R. B. (1978). Where does the customer fit in a service operation? Harvard Business Review, 56 (4), 137-142.

Darch, U., \& Caltabiano, N. (2004). Investigation of Automated Teller Machine banking in a sample of older adults. Australian Journal on Ageing. 23(2), 100-103.

Dilijonas, D., Kriksciunien, D., Sakalauskas, V., \& Simutis, R. (2009). Sustainability based service quality approach for Automated Teller Machine network. International Journal of Bank Marketing, 11(5), 43-57.

Hubbard, T. (2009). Introduction to the symposium on the competitive and welfare impacts of ATM fees. The Journal of Industrial Economics. 7(3), 553-556. 
Islam, R., Kumar, S., \& Biswas, P. K. (2007). Customer satisfaction of ATM service: A case study of HSBC ATM. international Journal of Bank Marketing, 7(5), 23-27.

Jegede, C. A. (2014). Effects of Automated Teller Machine on the performance of Nigerian banks. American Journal of Applied Mathematics and Statistics, 2(1), 40-46.

Jhandir, S. U. (2012). Customer satisfaction, perceived service quality and mediating role of perceived value. International Journal of Marketing Studies, 4 (1), 21-30.

Johnston, R. (1995). The zone of tolerance: Exploring the relationship between service transactions and satisfaction with the overal service. International Journal of Service Industry Management, 6 (2), 46-61.

Joseph, M., \& Stone, G. (2003). An empirical evaluation of US bank customer perceptions of the impact of technology on service delivery in the banking sector. International Journal of Retail and Distribution Management, 31(4), 190-202.

Jothi, L. (2016). Servic equality and customer satisfaction in life insurance business. Australian Journal of Basic and Applied Sciences, 10 (1), 636-641.

Koirala, K.D., \& Shrestha, S.K. (2012). Measuring service quality and customer satisfaction: Empirical evidence from Nepalese commercial banking sector undertakings. Management Dynamics, 16(1), 10-20.

Kumbhar, V. (2011). Factors affecting on customers' satisfaction: An empirical investigation of ATM service. International Journal of Business Economics and Management Research, 2(3), 144-156.

Madawaki, M., Audu, M. A., \& Oghoyone, A. S. (2014). The effects of customers experience on ATM refund system for failed bank transactions: A case of deposit money banks. Journal of Business and Management, 16(11), 50-67.

Mcandrews, J. (2003). Automated Teller Machine network pricing: A review of the literature. Review of Network Economics, 2(2), 146-158.

Motwani, D., \& Shrimali, D. (2013). Customer adoption and satisfaction towards ATM service: A comparative study of Udaipur City. Journal of Bank Marketing, 13(4), 33-40.

Omar, A. B., Sultan, N., Zaman, K., Bibi, N., Wajid, A., \& Khan, K. (2011). Customer perception towards online banking services: emperical evidence from Pakistan. Journal of Internet Banking and Commerce, 16 (2), 1-24.

Parvin, A., \& Hossain, S. (2010). Satisfaction of debit card users in Bangladesh: A study on some private commercial banks. Journal of Business and Technology,5(2), 88-103.

Raihan, A., Khan, S. R., Alam, M. R., \& Rabbi, K. (2001). Computerization and IT in banking sector: Hindrances and remedies. Bank Parikrama (Dhaka: BIBM), 26(1), 95-133.

Saeed, S., Azim, M., \& Choudhary, A. I. (2015). Service quality factors affecting adoption of internet banking in Pakistan. International Journal of Economics, Commerce and Management, 3 (2), 1-10.

Shamsuddoha, M., M. T. Chowdhury, \& Ahsan, A. B. (2005). Automated Teller Machine: A new dimension in the bank service of Bangladesh. Issues in Informing Science and Information Technology, 6(3), 75-83.

Singh, S. (2009). Impact of ATM on customer satisfaction: A comparative study of SBI, ICICI and HDFC bank. Business Intelligence Journal, 2(2), 276-287. 